\title{
Relative contribution of dengue prM- and E-specific polyclonal antibodies to neutralization and enhancement
}

\author{
P. RODPOTHONG ${ }^{1}$, CH. BOONARKART ${ }^{2}$, K. RUANGRUNG ${ }^{2}$, N. ONSIRISAKUL ${ }^{2}$, D. KANISTANON ${ }^{3}$, \\ P. AUEWARAKUL $2^{*}$
} ${ }^{1}$ Mahidol International College, Mahidol University, Thailand; ${ }^{2}$ Department of Microbiology, Faculty of Medicine Siriraj Hospital,
Mahidol University, Thailand; ${ }^{3}$ Department of Immunology, Faculty of Medicine Siriraj Hospital, Mahidol University, Thailand

Received September 28, 2015; revised May 5, 2016; accepted June 22, 2016

\begin{abstract}
Summary. - Viral surface proteins, premembrane protein (prM) and envelope (E) protein have been shown to induce a production of antibodies that are involved in both enhancement and neutralization. To explore the feasibility of modifying the relative immune responses to prM and E proteins, four DNA constructs were created and administered into groups of Balb/c mice; pPW01 contains prM and E genes of DENV1, pPW02 contains prM and E genes of DENV2, pPW03 contains DENV1 prM and DENV2 E, and pPW04 contains DENV2 prM and DENV1 E. Exchange of either prM or E from a heterologous serotype does not appear to have an effect on the immunogenicity of the proteins. We have proved that the chimeric pPW03 and pPW04 constructs can produce humoral response in mice. Immunized sera were subjected to neutralization and enhancement assays against DENV2. The results showed that only serotype-specific anti-E antibodies conferred protective function, while the cross-reactive anti-E and anti-prM enhanced infection. In addition, the enhancement of DENV2 infection exhibited a serotype-preference for anti-E antibodies while such response was not observed with antiprM, reflecting a degree of structural conservation of prM. Taken together, neutralization and enhancement appeared to occur at the same time during the course of infection. Successful prevention of severe symptoms of DENV infection depends on the ability to induce high levels of neutralizing antibodies to subdue the effect of enhancing antibodies.
\end{abstract}

Keywords: dengue; neutralization; enhancement; premembrane protein; envelope protein

\section{Introduction}

Dengue virus (DENV) is a mosquito-borne virus of the Flavivirus genus, consisting of four distinct serotypes, designated DENV1, DENV2, DENV3 and DENV4. The 11-kb viral genome is composed of positive-stranded RNA, encoding three structural proteins (C, prM and $\mathrm{E}$ ) and seven nonstructural proteins (NS1, 2A, 2B, 3, 4A, 4B and NS5) that are

*Corresponding author. E-mail: prasert.aue@mahidol.ac.th; phone: $+662-4419003$.

Abbreviations: $\mathrm{ADE}=$ antibody-dependent-enhancement; DENV = dengue virus; $\mathrm{DHF}=$ dengue hemorrhagic fever; $\mathrm{E}$ protein = envelope protein $; \mathrm{NT}=$ neutralization test prM $=$ premembrane protein involved in viral replication and pathogenesis (Lindenbach and Rice, 2003). During the viral replication, three types of particles can be found, immature, partially-mature and mature particles, which can be distinguished by the differences in size, surface morphology and the cleavage status of the premembrane (prM) protein that is associated with the envelope (E) protein on the surface of the virus (Lindenbach et al., 2007; Mukhopadhyay et al., 2005). The immature particles are spherical and spiky, where each spike is formed by a noncovalent association of three prM-E heterodimers with the pr part of prM on the outermost part of the spike. Infectious mature particles are formed when prM protein is cleaved into $\mathrm{M}$ protein and pr peptide. In mature particles, the $\mathrm{E}$ homodimers are arranged in groups of three parallel dimers in the "herringbone" structure (Kuhn et al., 2002; Li et al., 2008; Zhang et al., 2003). The partially-mature parti- 
cles contain approximately $30-40 \%$ of prM on the surface (Junjhon et al., 2010).

The prM protein has been shown to play an important role in enhancement of virus infection. Dejnirattisai et al. (2010) showed that monoclonal antibodies to prM isolated from secondary DENV-infected individuals, in general, do not neutralize infection, but cross-react among the four serotypes and potently promote enhancement (Dejnirattisai et al., 2010). We have also shown that the prM gene is more conserved among the four DENV serotypes than the E gene (Rodpothong and Auewarakul, 2012). This reflects a preserved function, and probably a cross-reactive and enhancing property of the prM protein. The E protein contains three domains, designated I, II and III. Domain I (EDI) is located in the center of the folded protein and contains the $\mathrm{N}$-terminus as well as it possesses glycosylation sites. This domain is flanked by domain II (EDII) that contains a conserved fusion loop that actively participates in the structural rearrangement during the viral fusion with an endosomal membrane. Domain III (EDIII) is located on the other side of the protein and exposed on the surface of the virion. This domain is an immunoglobulin-like domain that participates in receptor binding (Bressanelli et al., 2004; Modis et al., 2003). The prM and E genes have been important components of many versions of DNA vaccine candidates, such as a pcDNA3-based plasmid encoding the signal sequence of prM, prM and E genes, a recombinant plasmid expressing prM and truncated E genes. Those DNA vaccine candidates have successfully induced neutralizing antibodies and viremia protection against DENV in mice and rhesus macaque (Konishi et al., 2000, 2006; Raviprakash et al., 2000a,b).

Dengue virus causes a range of diseases, from the acute febrile illness - dengue fever (DF) to life-threatening dengue hemorrhagic fever (DHF) and dengue shock syndrome (DSS). Several studies have suggested that serious complications of DHF are linked to a secondary infection by a heterologous DENV serotype, and this secondary infection has been proposed to be a cause of the "antibody-dependent-enhancement" or ADE phenomenon (Guzman et al., 2000; Halstead and O'Rourke, 1977). During ADE the antibody elicited by the first infection is not sufficient to neutralize a secondary infection that is often caused by a different virus serotype (Diamond et al., 2008). To understand the nature of the virus-antibody interaction, several studies have isolated human monoclonal antibodies from both primary and secondary infections, and have investigated its ability to neutralize or enhance infection in cell cultures (Costin et al., 2013; Dejnirattisai et al., 2010; Rodenhuis-Zybert et al., 2011; Tsai et al., 2013). Animal models have also been employed to observe the outcome of the interaction, especially the ability to neutralize infection (Balsitis et al., 2010; Goncalvez et al., 2007; Zellweger et al., 2010). Observation on enhancement phenomenon has been limited in animal models because they do not develop DHF and DSS. Therefore, studies on polyclonal antibody responses in neutralization and especially enhancement have been minimal. In this study, we have used Balb/c mice to investigate the relative contribution of the polyclonal anti-prM and anti-E antibodies to neutralization and enhancement of DENV2 infection. Groups of mice were immunized with plasmid DNA constructs generated in this study. Mouse serum samples were collected for further assessing on their neutralizing and/or enhancing properties. Our study has strengthened our understanding in humoral immune response and may have an implication in DNA vaccine design.

\section{Materials and Methods}

Cell culture and virus. Aedes albopictus mosquito cells (C6/36) were grown at $28^{\circ} \mathrm{C}$ in Leibovitz 15 medium (Biochrom AG, Germany) supplemented with L-glutamine and $10 \%$ heat-inactivated fetal bovine serum (FBS). African green monkey kidney-derived Vero cells were propagated in modified Eagle's medium (MEM; Gibco, USA) supplemented with 10\% heat-inactivated FBS. U937 cells were cultured in RPMI-1640 medium (Gibco) supplemented with $10 \%$ heat-inactivated FBS. All cells were grown in a $5 \% \mathrm{CO}_{2}$ environment at $37^{\circ} \mathrm{C}$ or otherwise stated. DENV1 strain Hawaii and DENV2 strain 16681 were propagated in C6/36 cells. Viral supernatants were collected at day 5 and 7 after the infection. Virus titers were determined by immunostaining with monoclonal anti-E antibody 4G2 on Vero cell monolayer.

Plasmid DNA construction. All plasmid constructs contain a fulllength prM, including the prM signal sequence, and $\mathrm{E}$ gene under the cytomegalovirus promoter. The full-length genes were amplified from plasmid pBluescript II KS::DENV1 strain 03-0398 prM-E and plasmid pBluescriptII KS::DENV2 strain 03-0420 prM-E, using a standard overlapping PCR (O/V PCR) technique. Both pBluescript II KS plasmids were provided by the Faculty of Medicine at the University of Chiang Mai. DENV1 strain 03-0398 and DENV2 strain 03-0420 are isolates from Thai pediatric patients in 2003. These two DENV strains have previously been used to develop a chimeric live attenuated vaccine candidate, and have shown to induce significant levels of anti-DENV antibodies in mice and rhesus macaques (Keelapang et al., 2013). For the chimeric constructs, primer pairs were designed to perform O/V PCR to obtain chimeric DENV1prM-DENV2E and DENV2prM-DENV1E fragments (Table 1). The DENV1prMDENV2E and DENV2prM-DENV1E fragments are flanked by BsmBI-PflMI and BglII-PflMI restriction sites, respectively. The chimeric fragments were inserted into pBluescript II KS (Agilent Technology, USA) for further cloning. Additional primer pairs were designed to amplify the chimeric fragments from the pBluescript II KS constructs into the plasmid containing cytomegalovirus promoter (pCMV) for gene expression in eukaryotic cells. These primers contain a sequence of an efficient eukaryotic initiation site (ACCATG) and a prM signal sequence (NRRRRT) in the 5 ' primers, and a stop 
codon in the 3' primers. The PCR products are flanked by SalI-NotI restriction sites. For the control construct, the prM-E fragments were directly amplified from pBluescript II KS::DENV1 strain 030398 prM-E and pBluescript II KS::DENV2 strain 03-0420 prM-E. The recombinant pCMV constructs were confirmed by restriction enzyme digestion and sequencing.

Flow cytometry. To confirm the gene expression in eukaryotic cells, the constructs were transfected into HEK 293 cell line using transfection reagent Lipofectamin ${ }^{\star}$ (Invitrogen). Transfected cells were collected 3 days after transfection. Standard staining for flow cytometry was performed. Briefly, cells were washed 2 times with PBS, 3.7\% formaldehyde was added and incubated for $20 \mathrm{~min}$ at room temperature. Formaldehyde was discarded after the centrifugation, $0.2 \%$ Triton-X was added and the samples were further incubated for $20 \mathrm{~min}$ at room temperature and washed once with PBS again. Appropriate antibodies were added and incubated for $1 \mathrm{hr}$ at room temperature in the dark and then washed $1 \mathrm{x}$ with PBS. Secondary antibodies labeled with FITC (at $1: 300 \mathrm{~V} / \mathrm{V}$ ) were added and incubated for $1 \mathrm{hr}$ at room temperature in dark, washed once with PBS and finally $1.8 \%$ formaldehyde was added. All centrifugation steps were done at 1,500 rpm (Heraeus/Labofuge $400 \mathrm{R})$ at $25^{\circ} \mathrm{C}$ for $5 \mathrm{~min}$. In these assays we have used anti-E (4G2) and anti-prM (PrM6.1) antibodies. The 4G2 antibody is a group-specific anti-E antibody that recognizes an epitope located in or nearby the fusion loop (Trainor, 2007). The PrM6.1 reacts with the pr part of the prM protein (Junjhon et al., 2010). Cells were analyzed on FACSort (Becton Dickenson). The data were assessed with CellQuest software (Becton Dickenson).

Mouse immunization. Electroporation was selected as a DNA delivery method. This method utilizes electrical field to enhance the intracellular uptake of DNA within a target region of tissue. The electroporation procedure was performed, according to the manufacturer's instruction (Ichor Medical Systems, USA). The DNA constructs were electroporated into the anterior tibial muscle. Four Balb/c mice with the age of six to eight weeks from Department of Veterinary, Mahidol University were immunized three times at 2-week intervals with $50 \mu \mathrm{g}$ of a DNA construct. Mice were observed daily after immunization for signs of sickness or abnormality. Blood samples from healthy individual mice were collected using standard protocol for bleeding from both cheeks before immunization and 2-weeks after the last immunization. Sera were obtained through centrifugation of blood samples at 2,500 rpm using microcentrifuge for $10 \mathrm{~min}$. The immunization protocol was conducted in two independent experiments. Overall, eight mice were immunized with each individual DNA construct. Procedures with the animals were conducted in accordance with protocols approved by Siriraj Animal Care and Use Committee, which is in full compliance with International Guiding Principles for Biochemical Research Involving Animals (COA No. 013/2555).

Western blotting and dot blot. Standard dot blot and nondenaturing Western blot were employed to detect the presence of anti-DENV antibodies from pre- and post-immunization mouse sera, respectively. For Western blot, DENV supernatant was loaded onto a $10 \%$ polyacrylamide gel and transferred onto a nitrocellulose membrane. The blot was probed with 1:500 of a post-immunized serum sample or 4G2 as a primary antibody. For dot blot, the viral supernatant was dotted directly onto a nitrocellulose membrane and probed with 1:400 of a pre-immunization serum sample or 4G2. The DENV proteins were detected with secondary rabbit anti-mouse antibody conjugated with horseradish peroxidase (HRP, Dako) and visualized with the diaminobenzidine (DAB, Sigma).

Neutralization (NT) assay. NT was performed using Vero cells monolayer in microtitre plates. Briefly, mouse sera were heatinactivated and serially diluted 1:4 to 1:65536. Each dilution was incubated with virus $(2,000 \mathrm{ffu} / \mathrm{ml})$ at equal volume for $1 \mathrm{hr}$ at $37^{\circ} \mathrm{C}$. Fifty microliters of virus-serum mixture was added onto Vero cell monolayer $\left(3 \times 10^{4}\right.$ cells/well $)$ and incubated at $37^{\circ} \mathrm{C}$ for $2 \mathrm{hr}$. Then, $125 \mu$ l of overlay medium (1.5\% carboxy methyl cellulose in MEM supplemented with $2 \%$ heat-inactivated FBS) was added into each well. Cells were further incubated at $37^{\circ} \mathrm{C}, 5 \% \mathrm{CO}_{2}$ for $2-3$ days before immunostaining. The NT results were expressed as the highest serum dilution yielding at least $50 \%$ reduction in foci number. The p-values with 95\% confidence interval (using unpaired t-test) were calculated to determine the statistical significance between groups of immunized sera. Note that the sera were assessed for NT with both DENV1 strain Hawaii and DENV2 strain 16681. However, the NT data from DENV1 are not presented in this paper because some unidentified inhibitory factors in the mouse sera had interfered with the assay. These inhibitory factors appeared to be strain-specific as we did not observed the same effect with DENV2.

Antibody-dependent enhancement (ADE) assay. ADE was performed using U937 cells in microtitre plates with serially diluted mouse sera collected pre- and post-DNA administration. Sera were

Table 1. Primer sequences used to construct chimeric plasmids

\begin{tabular}{|c|c|}
\hline Primer name & Primer sequence \\
\hline PrM forward & $\begin{array}{l}\text { AAATTTGCCCTGGTGGCGTTCC } \\
\text { TTCGTTT }\end{array}$ \\
\hline O/V 0398PrM 0420E reverse & $\begin{array}{l}\text { G A T A T T C C T A T G C A A G C G A } \\
\text { TGGCCATGGATGGTGTTACCA }\end{array}$ \\
\hline O/V 0398PrM 0420E forward & $\begin{array}{l}\text { TGGTAACACCATCCATGGCCA } \\
\text { TGCGTTGCATAGGAATATC }\end{array}$ \\
\hline E reverse & $\begin{array}{l}\text { T T TA A ACC ATATAT T G G T G G } \\
\text { TGAATACTCC }\end{array}$ \\
\hline O/V 0420PrM 0398E reverse & $\begin{array}{l}\text { GCCTATTCCCACGCATCGCATTG } \\
\text { TCATTGAAGGAGCGACAGC }\end{array}$ \\
\hline O/V 0420PrM 0398E forward & $\begin{array}{l}\text { GCTGTCGCTCCTTCAATGACAA } \\
\text { TGCGATGCGTGGGATAGGC }\end{array}$ \\
\hline SalI primer forward & $\begin{array}{l}\text { AAATTTGTCGACACCATGACCA } \\
\text { TGAATAGGAGACGCAGATCTGCA }\end{array}$ \\
\hline NotI 0398E reverse & $\begin{array}{l}\text { TTTAAAGCGGCCGCTTACGCC } \\
\text { TGAACCATGACTCCTA }\end{array}$ \\
\hline NotI 0420E reverse & $\begin{array}{l}\text { TTTAAAGCGGCCGCTTAGGCC } \\
\text { TGCACCATGACTCCCAAATA }\end{array}$ \\
\hline
\end{tabular}

Highlighted nucleotides are restriction endonuclease sites, underlined nucleotides are an efficient eukaryotic initiation sequence, nucleotides encoding the prM signal sequence are in bold and nucleotides encoding the STOP codon are in italic. 
serially diluted at 1:5, 1:10, 1:100 to 1:104. Each dilution was incubated with virus at MOI of 1 at equal volume $(50 \mu \mathrm{l} \mathrm{each})$ for $1 \mathrm{hr}$ at $37^{\circ} \mathrm{C}$. The virus-serum mixture was then added to $2.5 \times 10^{4}$ cells (volume 100 $\mu \mathrm{l})$ and incubated at $37^{\circ} \mathrm{C}$ for 2 days. Infected cells without the addition of serum were used as a negative control. After the incubation period, cells were subjected to FAC staining with $4 \mathrm{G} 2$ antibody for detection of the viral E protein and Alexa Fluor ${ }^{\circledR} 488$ as a secondary antibody (Invitrogen). Briefly, cells were centrifuged at 2,000 rpm (Heraeus/Labofuge 400R) for 5 min, washed with FAC wash (PBS with $2 \%$ heat-inactivated FBS), treated with $3.7 \%$ formaldehyde for $20 \mathrm{~min}$ at room temperature, following treatment with $0.1 \%$ Triton-X for $10 \mathrm{~min}$ at room temperature, and washed with FAC wash. Primary antibody was added and incubated for $1 \mathrm{hr}$ at $4^{\circ} \mathrm{C}$ in the dark. Then the cells were washed with FAC wash, incubated in secondary antibody for $1 \mathrm{hr}$ at $4^{\circ} \mathrm{C}$ in the dark, washed with FAC wash and finally resuspended in FAC fix (PBS with 5\% formaldehyde).

Cells were analyzed on FACSort (Becton Dickenson, USA). The data were assessed with CellQuest software (Becton Dickenson).
Cells with fluorescence levels higher than negative control were DENV-infected cells. Serum dilution that gave out the highest percentage of fluorescent cells was considered as the peak of enhancement. The fold enhancement was calculated from the peak of enhancement and derived from:

$\%$ of positive cells in the presence of serum / $\%$ of positive cells in the absence of serum.

The p-values with $95 \%$ confidence interval (using unpaired t-test) were calculated to determine the statistical significance between groups of immunized sera.

\section{Results}

Plasmid construction and expression in HEK 293 T cells

Four different plasmid constructs were created in this study; pCMV::0398prM-E containing prM and E genes of
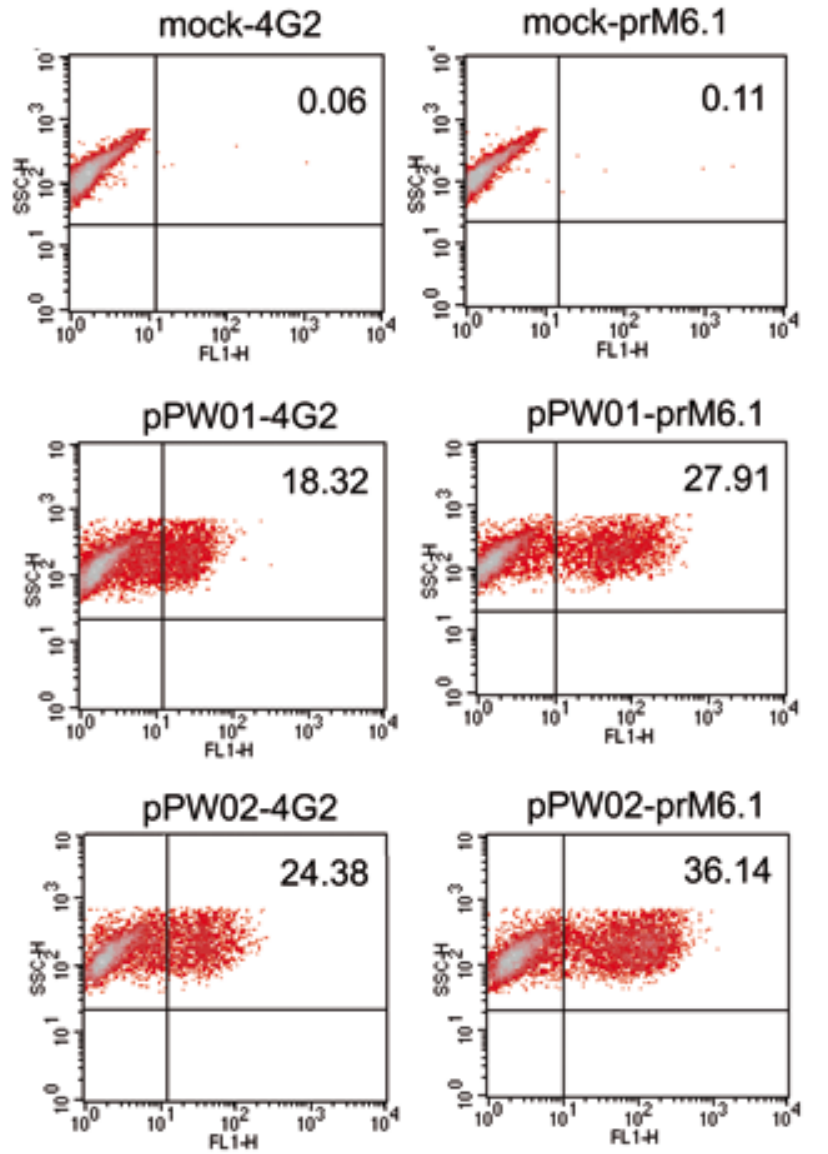
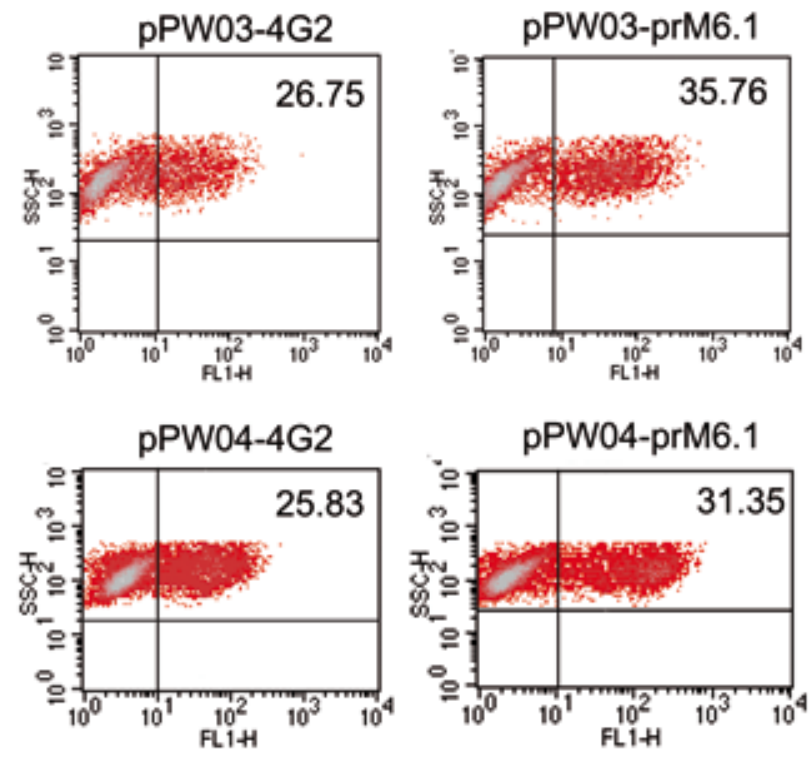

Fig. 1

Flow cytometer quadrant representation of HEK 293 T cells transfected with pPW01, pPW02, pPW03 and pPW04

The expression of prM and E was detected using two monoclonal antibodies (a) 4G2 and (b) PrM6.1. The percentages of positively fluorescent cells represent cells expressing prM and E proteins, and are shown in the upper right quadrant. Mock represents untransfected cells, which show no fluorescence. 
DENV1 strain 03-0398 (pPW01), pCMV::0420prM-E containing prM and E genes of DENV2 strain 03-0420 (pPW02), pCMV::0398prM0420E containing prM of DENV1 strain 03-0398 and E of DENV2 strain 03-0420 (pPW03), and pCMV::0420prM0398E containing prM of DENV2 strain 03-0420 and E of DENV1 strain 03-0398 (pPW04). Empty pCMV served as a control construct in this experiment.

The expression of the constructs was first assessed in HEK 293 T cells using Flow cytometry. Cells expressing viral proteins were identified by using two monoclonal antibodies, anti-E (4G2) and anti-prM (PrM6.1) (Fig. 1). HEK 293 T cells with no plasmid DNA transfection (mock) were used as a negative control to determine the cut off threshold, which is present in the upper left part of the quadrant. The positively fluorescent cells are present in the upper right part of the quadrant and the percentage of fluorescence is in the upper right corner. The positive fluorescent cells demonstrate the expression of both prM and E proteins.

\section{Plasmid constructs can induce anti-DENV antibodies}

All the pre-immunization sera were assessed for the presence of anti-DENV antibodies using dot blot. Probing with the monoclonal antibody $4 \mathrm{G} 2$ showed a dark spot, representing the presence of DENV proteins. In contrast, probing with the pre-immunization sera showed no signal, indicating that no anti-DENV antibodies were present in the pre-immunization sera (Fig. 2a). Non-denaturing Western blot was employed to detect the presence of anti-DENV antibodies in all post-immunized mouse sera. Positive control was probed with monoclonal antibodies $4 \mathrm{G} 2$, showing a band indicating the specific binding between 4G2 and DENV2 E protein. The post-immunized sera immunized with pPW01, pW02, pPW03 and pPW04 also showed a band at the same position as the control, suggesting the presence of anti-E antibodies (Fig. 2b). In contrast, the post-immunized sera immunized with pCMV showed no presence of antiDENV antibodies.

\section{Neutralization of DENV2}

The constructs were evaluated on their ability to induce neutralizing antibodies in Balb/c mice using the NT assay. The cut-off value for neutralization is at $50 \%$ reduction in foci forming units $\left(\mathrm{NT}_{50}\right)$. The NT titers expressing the maximum serum dilution yielding at least a $50 \%$ reduction in foci number are shown in Fig. 3. Sera immunized with pPW02 and pPW03 exhibited high NT titers, 1:4,096 and 1:1,024, respectively. Both groups are not significantly different from one another ( $\mathrm{p}$-value $=0.3622$ ), but are significantly different to sera immunized with pCMV ( $\mathrm{p}$-value $<0.0001$ ). In contrast, sera immunized with pPW01 and pPW04 showed low NT titers, 1:16 and 1:4, respectively, and showed no (a)

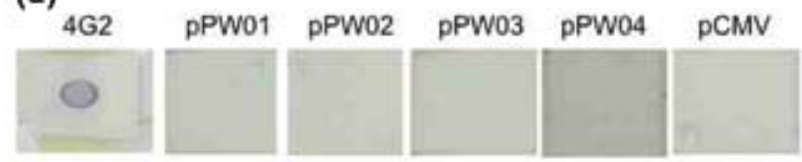

(b)

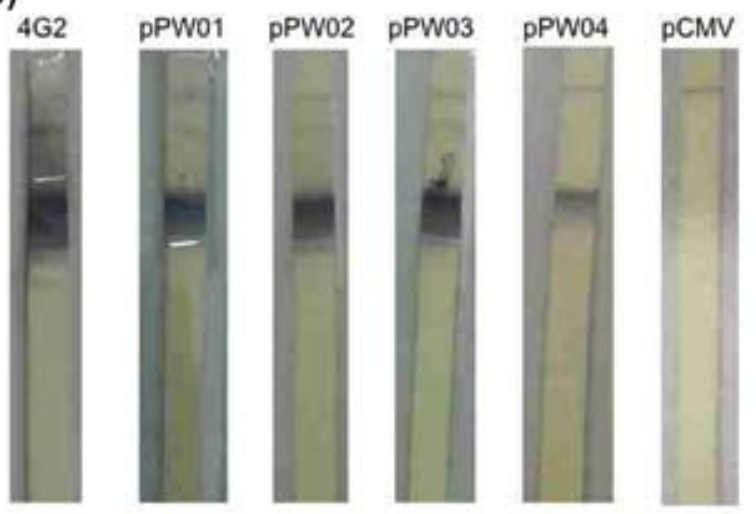

Fig. 2

Detection of anti-DENV2 antibodies in (a) pre-immunization sera using dot blot and (b) post-immunized sera using Western blot Monoclonal antibody 4G2 was used as a positive control to detect the presence of DENV2 proteins.

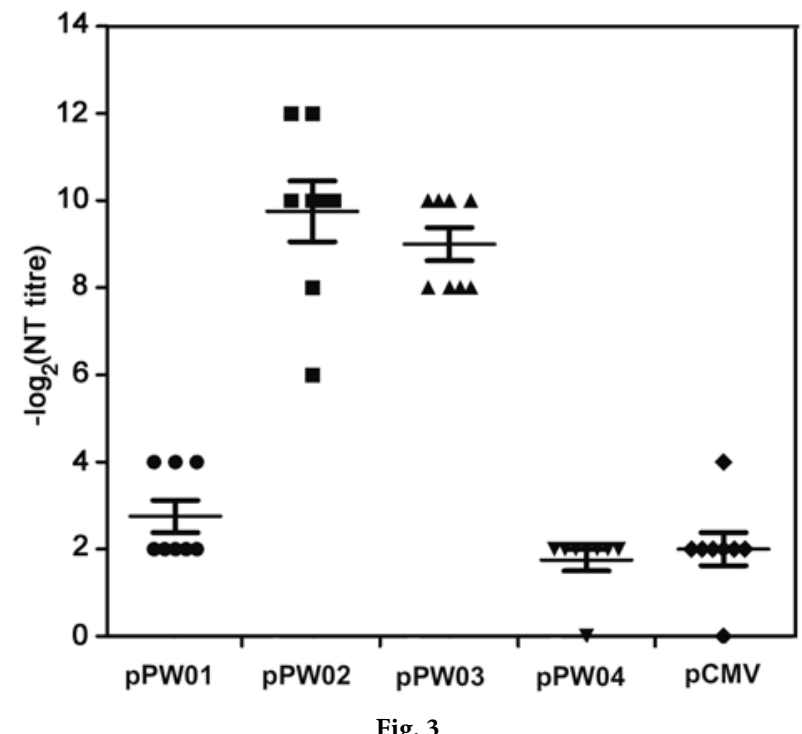

Neutralization titers of post-immunized sera from groups of 8 mice immunized with pPW01, pPW02, pPW03, pPW04 and pCMV

The NT titers represent the maximum serum dilution yielding at least a $50 \%$ reduction in foci number. The graph shows the results of two independent NT assays, using serum samples from two independent groups of Balb/c mice. The means and standard errors of mean (SEM) are shown in the graph. The p-value of each group of sera is described in the result section.

significant difference to that of pCMV ( $\mathrm{p}$-value >0.05). Pre-immunization sera showed a background neutralization titer of 1:4, but neutralizing activity decreased dramatically 

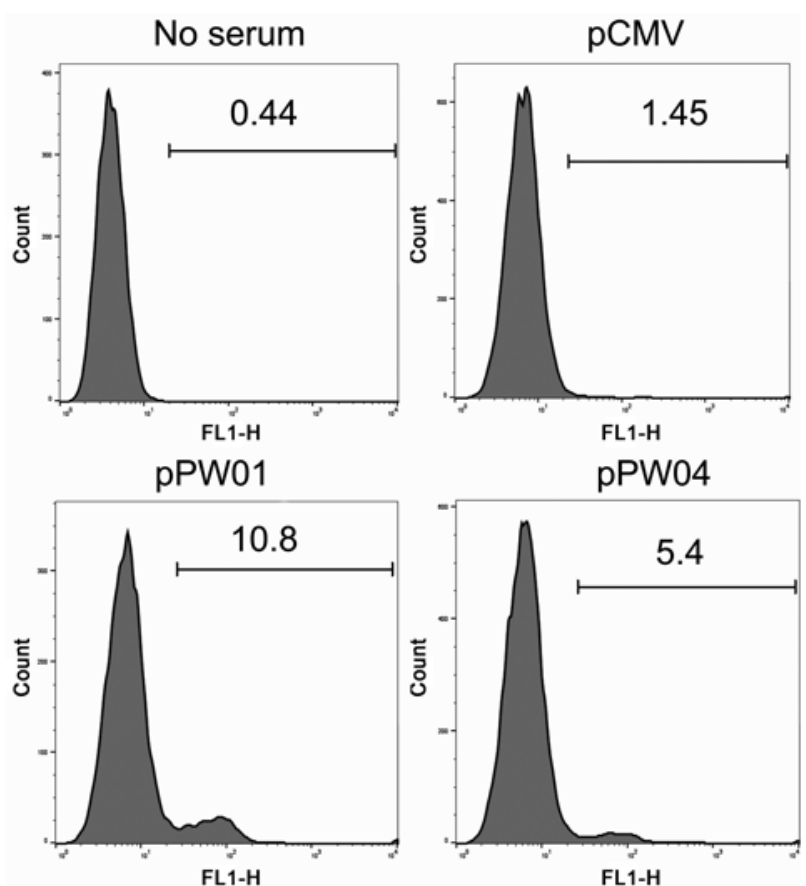

pPW02
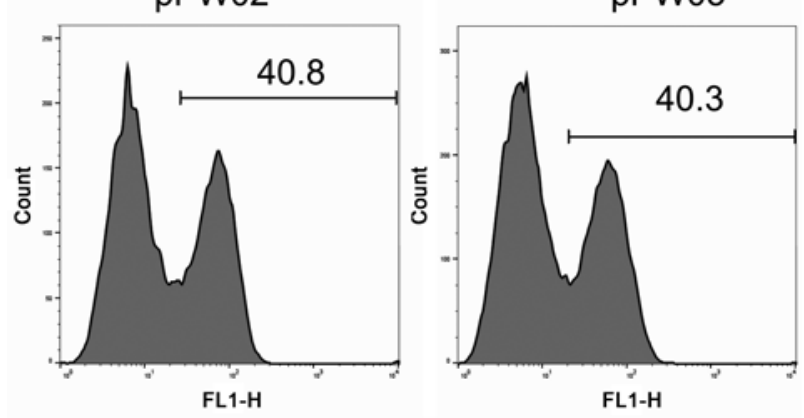

Fig. 4

Histogram shows the percentages of infected U937 T-cells in the absence or presence of sera immunized with different plasmid constructs

The graph shows serum dilution $1: 1,000$ or $1: 10,000$, where the highest percentages of infected cells were obtained (the peak of enhancement). "No serum" and pCMV sample show no infected cells, indicating no enhancement, while the others show some percentages of infected cells, indicating different degrees of enhancement.

when the sera were further diluted (data not shown). The background neutralization from pre-immunization sera was not the effect of anti-DENV antibodies because anti-DENV antibodies were not detected in these sera by dot blot.

\section{Antibody-dependent enhancement of DENV2}

Different serum dilutions were assessed for their ability to promote viral infection in U937 T-cells. The histogram shows the serum dilutions 1:1,000 or 1:10,000, which are the dilutions that enhance infection at the highest levels compared

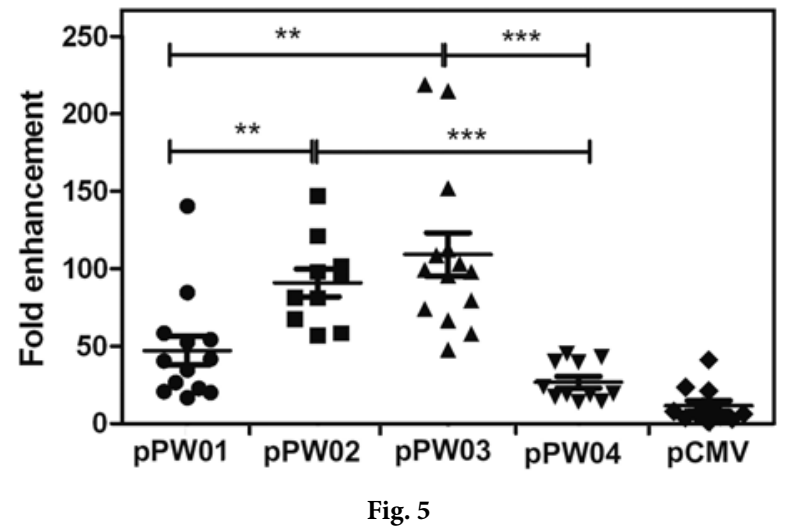

Fold enhancement of sera immunized with pPW01, pPW02, pPW03 pPW04 and pCMV

The assay was conducted in duplicate with serum samples from two independent groups of Balb/c mice. Thus, approximately 16 serum samples are shown in the graph for each DNA construct. The means, standard errors of mean (SEM) and the statistical differences between individual groups of sera are also shown. ${ }^{\star *}$ represents $\mathrm{p}$-value $<0.005$ and ${ }^{\star * *}$ represents p-value $<0.0001$.

to other serum dilutions (Fig. 4). These dilutions are referred to as the peaks of enhancement. Percentages of infected cells in the absence or presence of the post-immunized mouse sera are also shown in the graphs. Introduction of DENV2 to U937 cells in the absence of serum (No serum) and in the presence of sera derived from immunization with pCMV showed no presence of infection, indicating no enhancement. While the presence of sera derived from immunization with pPW01 pPW02 pPW03 or pPW04 promoted different degrees of infection, which reflected different degrees of enhancement.

Fold enhancement of the peak of enhancement is shown in Fig.5. The fold enhancement of sera immunized with pPW01, pPW02, pPW03 and pPW04 were significantly different to that of pCMV ( $\mathrm{p}$-value $<0.005$ ). The pPW02- and pPW03-derived sera exhibited high enhancement, with an average of 91-and 112-folds, respectively, and showed no significant difference from one another $(\mathrm{p}$-value $=0.3294)$. The pPW01- and pPW04-derived sera showed low enhancement, with an average of 52 and 27, respectively. The pPW01-derived sera also showed no significant difference to pPW04-derived sera $(\mathrm{p}$-value $=0.0737)$. Sera derived from mice immunized with pre-immunization sera showed no enhancement (data not shown).

\section{Discussion}

The prM and E proteins were successfully expressed from the four chimeric constructs in HEK293 cells. Two monoclonal antibodies 4G2 and PrM6.1 were used to detect the 
(a)

$\begin{array}{ll}\text { DEN1 } & 03-0398 \\ \text { DEN2 } & 0420 \\ \text { DEN2 } & 16681 \\ \text { DEN1 } & \text { CON } \\ \text { DEN2 } & \text { CON } \\ \text { DEN3 CON } & \text { DEN4 CON }\end{array}$

(b)

$\begin{array}{ll}\text { DEN1 } & 03-0398 \\ \text { DEN2 } & 0420 \\ \text { DEN2 } & 16681 \\ \text { DEN1 } & \text { CON } \\ \text { DEN2 } & \text { CON } \\ \text { DEN3 } & \text { CON } \\ \text { DEN4 } & \text { CON } \\ & \\ \text { DEN1 } & 03-0398 \\ \text { DEN2 } & 0420 \\ \text { DEN2 } & 16681 \\ \text { DEN1 } & \text { CON } \\ \text { DEN2 } & \text { CON } \\ \text { DEN3 } & \text { CON } \\ \text { DEN4 } & \text { CON }\end{array}$

PrM

1

F FHLTTRNGE PHMIVGIQEKGKSLLFKTEDGVNMCTLMAMDLGELCEDT T FHLTTRNGEPHMIVSRQEKGKSLLFKTEDGVNMCTLMAMDLGELCEDTIT FHLTTRGGEPHMIVSKQERGKSLLFKTSAGVNMCTLIAMDLGELCEDTMT FHLTTRNGEPHMIVSRQEKGKSLLFKTEDGVNMCTLMAMDLGELCEDT T FHLTSRDGE PRMIVGKNERGKSLLFKTASGINMCTLIAMDLGEMCDDTVT FHLSTRDGEPLMIVAKHERGRPLLFKTTEGINKCTLIAMDLGEMCEDTVT

\section{EDII}

101

125

150

WGNGCGLFGKGSLLTCAKFKCVTKLEGKIVQYENLKYSVIVTVHTGDQHQ WGNGCGLFGKGGIVTCAMETCKKNMEGKIVQPENLEYTIVVTPHSGEEHA WGNGCGLFGKGGIVTCAMERCKKNMEGKVVQPENLEYTIVITPHSGEEHA WGNGCGLFGKGSLITCAKFKCVTKLEGKIVQYENLKYSVIVTVHTGDQHQ WGNGCGLFGKGGIVTCAMETCKKNMEGKIVQPENLEYTIVITPHSGEEHA WGNGCGLFGKGSLVTCAKEQCLEPIEGKVVQYENLKYTVIITVHTGDQHQ WGNGCGLFGKGGVVTCAKESCSGKITGNLVQIENLEYTVVVTVHNGDTHA 201 225 250 MKEKSWLVHKQWFLDLPLPWTSGASTSQETWNRQDLLVTFKTAHAKKQEV MENKAWLVHRQWFLDLPLPWLPGADKQESNWIQKETLVTFKN PHAKKQDV MENKAWLVHRQWFLDLPLPWLPGA TQGSNWIQKETLVTFKN PHAKQDV MKEKSWLVHKQWFLDLPLPWTSGASTSQETWNRQDLLVTFKTAHAKKQEV MEDKAWLVHRQWFLDLPLPWLPGADTQGSNWIQKETLVTFKN PHAKQDV MKNKAWMVHRQWFFDLPLPWTSGATTET PTWNRKELLVTFKNAHAKKQEV MKKKTWLVHKQWFLDLPLPWTAGADTSEVHWNYKERMVTFKVPHAKRQDV

\section{EDIII}

294

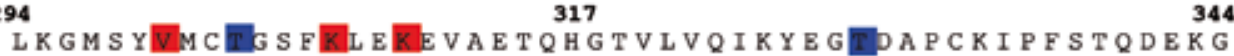

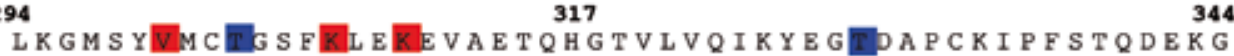
LKGMSYSMCTGKFKVVKEIAETQHGTIVIRVQYEG DGSPCKIPFEIMDLEK LKGMSYSMCTGKFKVVKEIAETQHGTIVIRVQYEGDGSPCKIPFEIMDLEK L K GMSYVIMCTGS FEL EREVAETQHGTVLVQVKY G TPAPCKIPFSTQDEKG LKGMSYSMCTGKFKVVKEIAETQHGTIVIRVQYEGDGSPCKI PFEIMDLEK LKGMSYAMCLNTEVLKKEVSETQHGTILIKVEYKGEDAPCKIPFSTEDGQG IKGMSYTMCSGKFSIDKEMAETQHGTTVVKVKYEGAGAPCKVPIEIRDVNK 345

368

VTQNGRLITANPIVTDKEKPVNIEAEPPFGSYIVIGAGEKALKSWFKG RYVLGRLITVNPIVTEKDSPVNIEAEPPFGDSYIIIGVEPGQLKLNWFKG RHVLGRLITVN P IVTEKDSPVNIEAEPPFGDSYIIIGVEPGQLKLNWFKKG VTQNGRLITAN P I T DKEKPVNIEAEPPFGESYIVVGAGEKLKLSWFKG RHVLGRIITVN P ITEKDSPVNIEAEPPFGDSYIIIGVEDGQLKLNWFKKG KAHNGRLITAN PVVTKKEEPVNIEAEPPFGESNIVIGIGDKALKINWYKKG EKVVGRVISSTPXAENTNSVTNIELEPPFGDSYIVIGVGNSALTLHWFRK

Fig. 6

Analysis of epitopes on (a) prM and (b) E genes

The sequence alignment consists of DENV1 strain 03-0398, DENV2 strain 03-0420, DENV2 strain 16681 and consensus sequences of DENV1-4. In (a) the epitopes are located within the first 50 amino acids of prM, and (b) the epitopes are in the EDII from amino acid 101-250 and EDIII from amino acid 294-396. Cross-reactive epitopes and residues are colored in yellow, type-specific are in red, and residues recognized by both cross-reactive and typespecific monoclonal antibodies are colored in blue. The yellow block represents a region between amino acids 19-34 as an enhancing antibody-binding site (Lin, 2012; Luo, 2013, 2015; Sukupolvi-Petty et al., 2007)

presence of the proteins. Cells positive in fluorescence indicate that $4 \mathrm{G} 2$ and PrM6.1 recognized their target epitopes on the prM and E complex. Thus, the exchange of either prM or E from a heterologous serotype does not have a major effect on the chimeric prM and E structure. The surface proteins prM and $\mathrm{E}$ have been used in several DNA vaccine 
constructs, such as a recombinant plasmid expressing prM and truncated $\mathrm{E}$ genes and a plasmid expressing only E gene (Kochel et al., 1997; Konishi et al., 2000, 2006; Raviprakash et al., 2000a). Interestingly, plasmids expressing only the $\mathrm{E}$ gene have been reported to induce a lower antibody response, compared to those expressing both prM and E genes. Thus, it appears that both prM and E are required to form highly immunogenic epitopes.

Serum samples derived from mice immunized with pPW01 (containing DENV1 prM and E) and pPW04 (containing DENV2 prM and DENV1 E) showed neutralizing titres similar to sera derived from pCMV immunization. This indicates that anti-DENV antibodies induced by these two constructs did not prevent virus infection. High neutralizing titres were observed in sera derived from the pPW02 (containing DENV2 prM and E) and pPW03 (containing DENV1 prM and DENV2 E) immunization, indicating a successful induction of anti-DENV antibodies that conferred a protective function. The neutralizing titers exhibited by these two constructs were comparable. Variation in the prM proteins did not make any detectable differences in the neutralizing ability of the sera. Thus, the neutralizing effect observed was likely a result of antibodies induced by DENV2 E protein and therefore, anti-E antibodies contributed significantly to neutralization of DENV infection. However, antibodies induced by DENV1 E protein did not exhibit a neutralizing activity to DENV2, which indicates that antibodies induced by E protein derived from the same virus serotype are more efficient to neutralize viruses of that serotype. This result is consistent with the finding that the protective antibodies are usually serotype-specific (Gromowski and Barret, 2007; Lai et al.,, 2008). The anti-prM antibodies induced by both DENV1 and DENV2 prM proteins did not appear to play a role in neutralization of DENV2 infection because sera derived from the pPW01 and pPW04 immunization did not exhibit high levels of neutralization. This is consistent with a study showing that the anti-prM antibodies isolated from secondary DENV-infected patients cannot neutralize infection (Dejnirattisai et al.,, 2010). The anti-prM antibodies are proposed to play an important role in enhancement of DENV infection, whereby the antibodies stimulate the binding of immature virus particles to cells through interaction with Fc $\gamma$ IIR receptors existing on various types of immune cells (Dejnirattisai et al., 2010; Huang et al., 2006; RodenhuisZybert et al., 2011).

All post-immunized sera enhanced DENV2 infection, suggesting a population of enhancing anti-DENV antibodies were also produced during the course of the immunization. Levels of enhancement observed with the immunized sera were likely a synergistic effect of both anti-prM and anti-E antibodies. However, a higher enhancement levels were observed with sera containing anti-E antibodies induced by DENV2 E protein, and a lower enhancement levels were observed with those induced by DENV1 E. These results suggest that the anti-E antibodies could cross-react with a heterologous serotype to enhance infection, but a higher enhancement levels were achieved with those of the homologous serotype. Therefore, there is a serotype-preference in enhancement. This population of enhancing anti-DENV antibodies may recognize epitopes on the surface proteins that are different to those recognized by the protective antiDENV population. Monoclonal antibody studies suggest that strong neutralizing antibodies usually bind to EDIII epitope, while those that recognize EDI and II neutralized poorly and show broad cross-reactivity with the other four serotypes (Crill and Roehrig, 2001; Hiramatsu et al., 1996). Fig. 6b shows epitope residues on EDII and EDIII that are recognized by type-specific and cross-reactive panels of mouse monoclonal antibodies (Lin et al., 2012; Sukupolvi-Petty et al., 2007). The EDIII also contains epitope residues that can be recognized by cross-reactive antibodies, which have very poor to no neutralizing activity. Some epitope residues can also be recognized by both type-specific and cross-reactive antibodies. Comparing to human polyclonal antibody, only $5-15 \%$ of neutralizing activity in human immune sera have been shown to target EDIII (Midgley et al., 2011; Wahala et al., 2009). These EDIII epitopes are not the main target for human neutralizing antibodies (Sukupolvi-Petty et al,, 2007, 2010; Wahala et al., 2012). Of all the epitope residues presented in Fig. 6b, only W101, L107 and F108 can be recognized by human anti-E antibodies from DENV-infected sera (Lin et al.,, 2012).

The enhancing activity exhibited by the DENV1 anti-prM antibodies showed no major difference to those of DENV2, implicating that anti-prM antibodies had no serotype preference. This may reflect a more conserved sequence and enhancing epitopes of prM across the four serotypes (Rodpothong and Auewarakul, 2012). Luo et al. (2013) characterized a prM enhancing epitope at amino acid positions 14-18 of DENV1-4 prM using phage-displayed peptide library and a bioinformatic analysis (Luo et al., 2013). These binding motifs were also DENV serocomplex cross-reactive. In addition, Luo et al. (2015) used a peptide scaning approach to identify a region between amino acids 19-34 of DENV2 prM that can be recognized by anti-DENV from all four serotypes, and showed that these anti-DENV antibodies were infection-enhancing antibodies (Luo et al., 2015).

The outcome of the polyclonal antibody response may be different to those of monoclonal antibody response due to complex interaction between different types of antibodies and epitopes. Humoral response to DNA constructs may also be different to the natural humoral response. Whether prM-E DNA constructs produce the same immunogenic epitopes or the prM has been cleaved at the same percentage as a live virus are not fully known. These variations will affect types and amount of antibodies being produced. In addition, flavi- 
viruses are known to exist as a group of related structures at equilibrium that arise from the dynamic motion of $E$ proteins that comprise the antigenic surface of the mature virion. This mechanism varies the exposure of antigenic sites available for antibody binding, impacts the ability of antibodies to neutralize infection, and may contribute to the underlying mechanisms of strain-dependent neutralization sensitivity (Dowd et al., 2014).

This study showed that a multiple immunization of surface antigens from a homologous serotype induced polyclonal populations of antibodies that conferred both protective and enhancing properties. Therefore, this would indicate that neutralization and enhancement occurred at the same time during the course of infection. Neutralization would be an overall outcome if the protective antibodies were more effective in preventing virus infection. It would thus mask the effect of antibody-dependent enhancement. Similarly, if the enhancing antibodies were more efficient, neutralization would be subdued. Previous studies reported that severe signs of DENV infection are often observed during a secondary infection by a heterologous serotype, indicating that the enhancing populations of antibodies may get amplified. In fact, it has been shown that in the presence of a heterologous serotype, somatic hypermutations in the existing memory $\mathrm{B}$ cells are triggered to dominantly secrete populations of crossreactive antibodies with a higher avidity to the heterologous serotype and also to amplify the prM response (Mathew et al., 2011). These populations of antibodies stimulate enhancement of the heterologous serotype, supersede neutralization and thus contributes to severe disease symptoms. A successful tetravalent vaccine containing the prM and $\mathrm{E}$ of all four DENV serotypes should be able to induce strong neutralizing antibodies that are effective enough to subdue enhancement and to prevent infection in the presence of cross-reactive antibodies.

In conclusion, this study demonstrated that a chimeric construct containing prM or E of a heterologous serotype can induce an antibody response as well as those of a homologous serotype. In the course of immunization with different prM-E DNA constructs, both protective and enhancing antibodies were induced. The serotype-specific anti-E antibodies contributed to the ability to neutralize virus infection, while cross-reactive anti-E and anti-prM antibodies contributed to enhancement. In addition, we showed that anti-E antibodies induced by a homologous serotype enhanced infection of that serotype better than a heterologous serotype, indicating a serotype-preference in enhancement.

Acknowledgements. This work was supported by the Office of the Higher Education Commission and Mahidol University under the National Research Universities Initiative, a research grant from the Thailand Research Fund (RTA5780009), and Siriraj research fund, Faculty of Medicine Siriraj Hospital, Mahidol University. P.
Rodpothong thanks Dr. Nopporn Sittisombut for pBluescript II KS:: DENV prM-E plasmids, Dr. Chunya Puttikhunt for monoclonal antibodies, 4G2 and PrM6.1 and Dr. Prida Malasit for DENV used in this study.

\section{References}

Balsitis SJ, Williams KL, Lachica R, Flores D, Kyle JL, Mehlhop E, Johnson S, Diamond MS, Beatty PR, Harris E (2010): Lethal antibody enhancement of dengue disease in mice is prevented by Fc modification. PLoS Pathog. 6, e1000790. http://dx.doi.org/10.1371/journal.ppat.1000790

Bressanelli S SK, Allison SL, Stura EA, Duquerroy S, Lescar J, Heinz FX, Rey FA (2004): Structure of a flavivirus envelope glycoprotein in its low-pH-induced membrane fusion conformation. EMBO J. 23, 728-738. http://dx.doi. org/10.1038/sj.emboj.7600064

Costin JM ZE, Kahle KM, Nicholson CO, Rowe DK, Graham AS, Bazzone LE, Hogancamp G, Figueroa Sierra M, Fong RH, Yang ST, Lin L, Robinson JE, Doranz BJ, Chernomordik LV, Michael SF, Schieffelin JS, Isern S (2013): Mechanistic study of broadly neutralizing human monoclonal antibodies against dengue virus that target the FL. J. Virol. 87, 52-66. http://dx.doi.org/10.1128/JVI.02273-12

Crill WD, Roehrig JT (2001): Monoclonal antibodies that bind to domain III of dengue virus E glycoprotein are the most efficient blockers of virus adsorption to Vero cells. J. Virol. 75, 7769-7773. http://dx.doi.org/10.1128/JVI.75.16.7769$\underline{7773.2001}$

Dejnirattisai W, Jumnainsong A, Onsirisakul N, Fitton P, Vasanawathana S, Limpitikul W, Puttikhunt C, Edwards C, Duangchinda T, Supasa S, Chawansuntati K, Malasit P, Mongkolsapaya J, Screaton G (2010): Cross-reacting antibodies enhance dengue virus infection in humans. Science 328, 745-748. http://dx.doi.org/10.1126/science. 1185181

Diamond MS, Pierson TC, Fremont DH (2008): The structural immunology of antibody protection against West Nile virus. Immunol. Rev. 225, 212-225. http://dx.doi. org/10.1111/j.1600-065X.2008.00676.X

Dowd KA, Mukherjee S, Kuhn RJ, Pierson TC (2014): Combined effects of the structural heterogeneity and dynamics of flaviviruses on antibody recognition. J. Virol. 88, 117261137. http://dx.doi.org/10.1128/JVI.01140-14

Goncalvez AP, Engle RE, St Claire M, Purcell RH, Lai CJ (2007): Monoclonal antibody-mediated enhancement of dengue virus infection in vitro and in vivo and strategies for prevention. Proc. Natl. Acad. Sci. USA 104, 9422-9427. http://dx.doi.org/10.1073/pnas.0703498104

Gromowski GD, Barret AD (2007): Characterization of an antigenic site that contains a dominant, type-specific neutralization determinant on the envelope protein domain III (ED3) of dengue 2 virus. Virology 366, 349-360. http://dx.doi. org/10.1016/j.virol.2007.05.042

Guzman MG, Kouri G, Valdes L, Bravo J, Alvarez M, Vazques S, Delgado I, Halstead SB (2000): Epidemiologic 
studies on Dengue in Santiago de Cuba, 1997. Am. J. Epidemiol. 152, 793-739. http://dx.doi.org/10.1093/ aje/152.9.793

Halstead SB, O'Rourke EJ (1977): Antibody-enhanced dengue virus infection in primate leukocytes. Nature 265, 739-741. http://dx.doi.org/10.1038/265739a0

Hiramatsu K, Tadano M, Men R, Lai CJ (1996): Mutational analysis of a neutralization epitope on the dengue type 2 virus (DEN2) envelope protein: monoclonal antibody resistant DEN2/DEN4 chimeras exhibit reduced mouse neurovirulence. Virology 224, 437-445. http://dx.doi. org/10.1006/viro.1996.0550

Huang KJ, Yang YC, Lin YS, Huang JH, Liu HS, Yeh TM, Chen SH, Liu CC, Lei HY (2006): The dual-specific binding of dengue virus and target cells for the antibodydependent enhancement of dengue virus infection. J. Immunol. 176, 2825-2832. http://dx.doi.org/10.4049/ jimmunol.176.5.2825

Junjhon J, Edwards TJ, Utaipat U, Bowman VD, Holdaway HA, Zhang W, Keelapang P, Puttikhunt C, Perera R, Chipman PR, Kasinrerk W, Malasit P, Kuhn RJ, Sittisombut $\mathrm{N}$ (2010): Influence of pr-M cleavage on the heterogeneity of extracellular dengue virus particles. J. Virol. 84, 8353-8358. http://dx.doi.org/10.1128/JVI.00696-10

Keelapang P, Nitatpattana N, Suphatrakul A, Punyahathaikul S, Sriburi R, Pulmanausahakul R, Pichyangkul S, Malasit P, Yoksan S, Sittisombut N (2013): Generation and preclinical evaluation of a DENV-1/2 prM+E chimeric live attenuated vaccine candidate with enhanced prM cleavage. Vaccine 31, 5134-5140. http://dx.doi.org/10.1016/j. vaccine.2013.08.027

Kochel T, Wu S-J, Raviprakash K, Hobart P, Hoffman S, Porter K, Hayes C (1997): Inoculation of plasmids expressing the dengue-2 envelope gene elicit neutralizing antibodies in mice. Vaccine 15, 547-552. http://dx.doi.org/10.1016/ $\underline{\text { S0264-410X(97)00215-6 }}$

Konishi E, Kosugi S, Imoto J-I (2006): Dengue tetravalent DNA vaccine inducing neutralizing antibody and anamnestic responses to four serotypes in mice. Vaccine 24, 2200-2207. http://dx.doi.org/10.1016/j.vaccine.2005.11.002

Konishi E, Yamaoka M, Kurane I, ason PW (2000): A DNA vaccine expressing dengue type 2 virus premembrane and envelope genes induces neutralizing antibody and memory B cells in mice. Vaccine 18, 1133-1139. http://dx.doi. org/10.1016/S0264-410X(99)00376-X

Kuhn RJ, Zhang W, Rossmann MG, Pletnev SV, Corver J, Lenches E, Jones CT, Mukhopadhyay S, Chipman PR, Strauss EG, Baker TS, Strauss JH (2002): Structure of dengue virus: implications for flavivirus organization, maturation, and fusion. Cell 108, 717-725. http://dx.doi.org/10.1016/ S0092-8674(02)00660-8

Lai CY, Tsai W, Lin SR, Kao CL, Hu HP, King CC, Wu HC, Chang GJ, Wang WK (2008): Antibodies to envelope glycoprotein of dengue virus during the natural course of infection are predominantly cross-reactive and recognize epitopes containing highly conserved residues at the fusion loop of domain II. J. Virol. 82, 6631-6643. http://dx.doi. org/10.1128/JVI.00316-08
Li L, Lok S-M, Yu I-M, Zhang Y, Kuhn RJ, Chen J, Rossmann MG (2008): The flavivirus precursor membrane-envelope protein complex: structure and maturation. Science 319 , 1830-1834. http://dx.doi.org/10.1126/science.1153263

Lin HE, Tsai W, Liu IJ, Li PC, Liao MY, Tsai JJ, Wu YC, Lai CY, Lu $\mathrm{CH}$, Huang JH, Chang GJ, Wu HC, Wang WK (2012): Analysis of epitopes on dengue virus envelope protein recognized by monoclonal antibodies and polyclonal human sera by a high throughput assay. PLoSNegl. Trop. Dis. 6, e1447. http://dx.doi.org/10.1371/journal. pntd.0001447

Lindenbach BD, Thiel HJ, Rice CM (2007): Flaviviridae: the viruses and their replication. In Knipe DM, Howley PM(Ed.): Fields Virology, Lippincott-Raven, Philadelphia, PA.

Lindenbach BD, Rice CM (2003): Molecular biology of flaviviruses. Adv. Virus Res. 59, 23-61. http://dx.doi.org/10.1016/ $\underline{\text { S0065-3527(03)59002-9 }}$

Luo Y, Guo X, Yan H, Fang D, Zeng G, Zhou J, Jiang L (2015): Comprehensive mapping infection-enhancing epitopes of dengue pr protein using polyclonal antibody against prM. Appl. Microbiol. Biotechnol. 99, 5917-5927. http:// dx.doi.org/10.1007/s00253-015-6538-9

Luo YY, Feng JJ, Zhou JM, Yu ZZ, Fang DY, Yan HJ, Zeng GC, Jiang LF (2013): Identification of a novel infection-enhancing epitope on dengue prM using a dengue cross-reacting monoclonal antibody. BMC Microbiol. 13, 194. http:// dx.doi.org/10.1186/1471-2180-13-194

Mathew A, West K, Kalayanarooj S, Gibbons RV, Srikiatkhachorn A, Green S, Libraty D, Jaiswal S, Rothman AL (2011): $\mathrm{B}$-cell responses during primary and secondary dengue virus infections in humans. J. Infect. Dis. 204, 1514-1522. http://dx.doi.org/10.1093/infdis/jir607

Midgley CM, Bajwa-Joseph M, Vasanawathana S, Limpitikul W, Wills B, Flanagan A, Waiyaiya E, Tran HB, Cowper AE, Chotiyarnwong P, Grimes JM, Yoksan S, Malasit P, Simmons CP, Mongkolsapaya J, Screaton GR (2011): An in-depth analysis of original antigenic sin in dengue virus infection. J. Virol. 85, 410-421. http://dx.doi.org/10.1128/ JVI.01826-10

Modis Y, Steven O, Clements D, Harrison SC (2003): A ligandbinding pocket in the dengue virus envelope glycoprotein. Proc. Natl. Acad. Sci. USA. 100, 6986-6991. http://dx.doi. org/10.1073/pnas.0832193100

Mukhopadhyay S, Kuhn RJ, Rossmann MG (2005): A structural perspective of the flavivirus life cycle. Nat. Rev. Microbiol. 3, 13-22. http://dx.doi.org/10.1038/nrmicro1067

Raviprakash K, Kochel TJ, Ewing D, Simmons M, Phillips I, Hayes CG, Porter KR (2000a): Immunogenicity of dengue virus type 1 DNA vaccines expressing truncated and full length envelope protein. Vaccine 18, 2426-2434. http://dx.doi. org/10.1016/S0264-410X(99)00570-8

Raviprakash K, Porter KR, Kochel TJ, Ewing D, Simmons M, Phillips I, Murphy GS, Weiss WR, Hayes CG (2000b): Dengue virus type 1 DNA vaccine induces protective immune responses in rhesus macaques. J. Gen. Virol. 81, 1659-1667. http://dx.doi.org/10.1099/0022-1317-81-7-1659

Rodenhuis-Zybert IA MB, da Silva Voorham JM, van derEndeMetselaar H, Diamond MS, Wilschut J, Smit JM (2011): 
A fusion-loop antibody enhances the infectious properties of immature flavivirus particles. J. Virol. 85, 11800-11808. http://dx.doi.org/10.1128/JVI.05237-11

Rodpothong P, Auewarakul P (2012): Positive selection sites in the surface genes of dengue virus: phylogenetic analysis of the interserotypic branches of the four serotypes. Virus Genes 44, 408-414. http://dx.doi.org/10.1007/s11262011-0709-2

Sukupolvi-Petty S, Austin SK, Engle M, Brien JD, Dowd KA, Williams KL, Johnson S, Rico-Hesse R, Harris E, Pierson TC, Fremont DH, Diamond MS (2010): Structure and function analysis of therapeutic monoclonal antibodies against dengue virus type 2. J. Virol. 84, 9227-9239. http:// dx.doi.org/10.1128/JVI.01087-10

Sukupolvi-Petty S, Austin SK, Purtha WE, Oliphant T, Nybakken GE, Schlesinger JJ, Roehrig JT, Gromowski GD, Barrett AD, Fremont DH, Diamond MS (2007): Type- and subcomplex-specific neutralizing antibodies against domain III of dengue virus type 2 envelope protein recognize adjacent epitopes. J. Virol. 81, 12816-12826. http://dx.doi. org/10.1128/JVI.00432-07

Trainor NB, Crill WD, Roberson JA, Chang GJJ (2007): Mutation analysis of the fusion domain region of St. Louis encephalitis virus envelope protein. Virology 360, 398-406. http:// dx.doi.org/10.1016/j.virol.2006.10.033
Tsai WY LC, Wu YC, Lin HE, Edwards C, Jumnainsong A, Kliks S, Halstead S, Mongkolsapaya J, Screaton GR, Wang WK (2013): High-avidity and potently neutralizing crossreactive human monoclonal antibodies derived from secondary dengue virus infection. J. Virol. 87, 12562-12575. http://dx.doi.org/10.1128/JVI.00871-13

Wahala WM, Huang C, Butrapet S, White LJ, de Silva AM (2012): Recombinant dengue type 2 viruses with altered e protein domain III epitopes are efficiently neutralized by human immune sera. J. Virol. 86, 4019-4023. http://dx.doi. org/10.1128/JVI.06871-11

Wahala WM, Kraus AA, Haymore LB, Accavitti-Loper MA, de Silva AM (2009): Dengue virus neutralization by human immune sera: role of envelope protein domain IIIreactive antibody. Virology 392, 103-113. http://dx.doi. org/10.1016/j.virol.2009.06.037

Zellweger RM, Prestwood TR, Shresta S (2010): Enhanced infection of liver sinusoidal endothelial cells in a mouse model of antibody-induced severe dengue disease. Cell Host Microbe 7, 128-139. http://dx.doi.org/10.1016/j. chom.2010.01.004

Zhang Y, Corver J, Chipman PR, Zhang W, Pletnev SV, Sedlak D, Baker TS, Strauss JH, Kuhn RJ, Rossmann MG (2003): Structures of immature flavivirus particles. EMBO J. 22, 2604-2613. http://dx.doi.org/10.1093/emboj/cdg270 